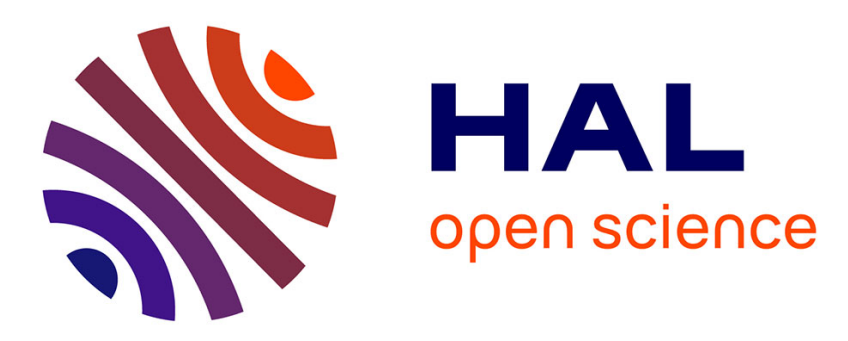

\title{
Chemical Vapour Deposition of Thick Tungsten Coatings : Raman Measurements and Mass Transport Modelling
}

\author{
M. Pons, A. Benezech, P. Huguet, R. Gaufres, Ph. Diez, D. Lafforet
}

\section{- To cite this version:}

M. Pons, A. Benezech, P. Huguet, R. Gaufres, Ph. Diez, et al.. Chemical Vapour Deposition of Thick Tungsten Coatings: Raman Measurements and Mass Transport Modelling. Journal de Physique IV Proceedings, 1995, 05 (C5), pp.C5-143-C5-150. 10.1051/jphyscol:1995515 . jpa-00253840

\author{
HAL Id: jpa-00253840 \\ https://hal.science/jpa-00253840
}

Submitted on 1 Jan 1995

HAL is a multi-disciplinary open access archive for the deposit and dissemination of scientific research documents, whether they are published or not. The documents may come from teaching and research institutions in France or abroad, or from public or private research centers.
L'archive ouverte pluridisciplinaire HAL, est destinée au dépôt et à la diffusion de documents scientifiques de niveau recherche, publiés ou non, émanant des établissements d'enseignement et de recherche français ou étrangers, des laboratoires publics ou privés. 


\title{
Chemical Vapour Deposition of Thick Tungsten Coatings: Raman Measurements and Mass Transport Modelling
}

\author{
M. Pons, A. Benezech, P. Huguet*, R. Gaufres*, Ph. Diez** and D. Lafforet** \\ Laboratoire Science des Surfaces et Matériaux Carbonés, URA 413 du CNRS, ENSEEG - INPG, B.P.75, \\ 38402 Saint-Martin d'Hères, France \\ * Laboratoire de Spectrométrie Moléculaire, USTL, Place Eugène Bataillon, 34095 Montpellier, France \\ ** COMURHEX, B.P. 29, 26701 Pierrelatte, France
}

\begin{abstract}
Thick tungsten coatings have been produced by chemical vapour deposition (CVD) from $\mathrm{H}_{2}-\mathrm{WF}_{6}$ at a temperature in the range $773-1073 \mathrm{~K}$ under a reduced pressure. The experimental set-up is designed for in situ Raman analysis of the gas phase (temperature and $W F_{6}$ concentration) during the growth of tungsten coatings. A two dimensional mass transport model was proposed. It assumes a simple chemical pathway. Only the $H_{2}$ reduction of $\mathrm{WF}_{6}$ has been taken into account. The major objective of the paper is to report on the comparison between (i) the experimental deposition rate and the deposition rate predicted by the model, (ii) the values of temperature and gas phase composition deduced from Raman spectroscopy measurements and the values of these quantities obtained by numerical calculations. These comparisons have shown the predictive capabilities of the numerical modelling and that the temperature and $\mathrm{WF}_{6}$ partial pressures can be recorded by a Raman equipment during the deposition process.
\end{abstract}

\section{INTRODUCTION}

In recent years, there has been a considerable interest, for microelectronics, in depositing blanket tungsten films by chemical vapour deposition (CVD) in the $10^{2}-10^{3} \mathrm{~Pa}$ range at temperatures between 673 and $773 \mathrm{~K}$ [1-5]. Tungsten is a suitable candidate for metallization in microelectronics thanks to its relatively low resistivity, good electromigration resistance and its thermal expansion coefficient similar to that of silicon. CVD is also used to manufacture self-supported components with a poor workability such as tungsten. Thick deposits of tungsten (up to $5 \mathrm{~mm}$ ) have been obtained under different operating conditions (temperatures, partial pressures, flow rates, reactor geometry ...) [6].

Recently, numerical models for CVD of tungsten, at a temperature in the range $600-800 \mathrm{~K}$ under a reduced total pressure varying from 100 to $1000 \mathrm{~Pa}$, have been presented based upon some combination of heat, mass and momentum transfer [7-10]. Fotiadis et al. [7] have already compared Raman measurements and numerical predictions in a CVD reactor. By linking the conservation equations to kinetic data, these models have been used to optimise the process and the equipment [8-10]. Industrial equipment for selective tungsten deposition have been optimised by accurate modelling studies including not only the main reactive species $\left(\mathrm{H}_{2}, \mathrm{WF}_{6}\right.$ and $\left.\mathrm{HF}\right)$ but also reactive intermediates $\mathrm{WF}_{\mathrm{x}}$ and $\mathrm{SiF}$ which are considered responsible for selectivity loss [10]. The calculations have shown that it is possible to reduce the HF concentration by changes in the reactor design.

When moving towards a high temperature range $(773 \mathrm{~K}-1073 \mathrm{~K})$, even using higher $\mathrm{WF}_{6}$ pressures, the $\mathrm{H}_{2}$ reduction reaction pathway may enter the diffusion controlled regime. It is the aim of this study to delimit the different regimes in the $773 \mathrm{~K}-1073 \mathrm{~K}$ temperature range and to report on the results obtained by mass transport modelling, deposition experiments and in-situ Raman diagnostics. In the range of temperature and pressure investigated in this work, measurements from spectral signals originating from spontaneous Raman effect are usually considered as very bad. or even impossible. due to the weakness of Raman scattering by such media. Non-linear techniques, such as Coherent Anti-Stokes Raman Scattering (C.A.R.S.) were generally used [11]. As it was pointed out by Oosterlaken et al. [12], the use of Raman scattering for the determination of gas mixture composition at low pressure. elevated temperature and short 
sampling times has become feasible with the introduction of high power laser. In this work, we have conceived an intra-cavity equipment using spontaneous Raman scattering of such a detectivity that we were able to record a fair spectrum of the vapour of a good scatterer $\left(\mathrm{C}_{10} \mathrm{H}_{8}\right)$ under a pressure of $11.5 \mathrm{~Pa}$ at room temperature.
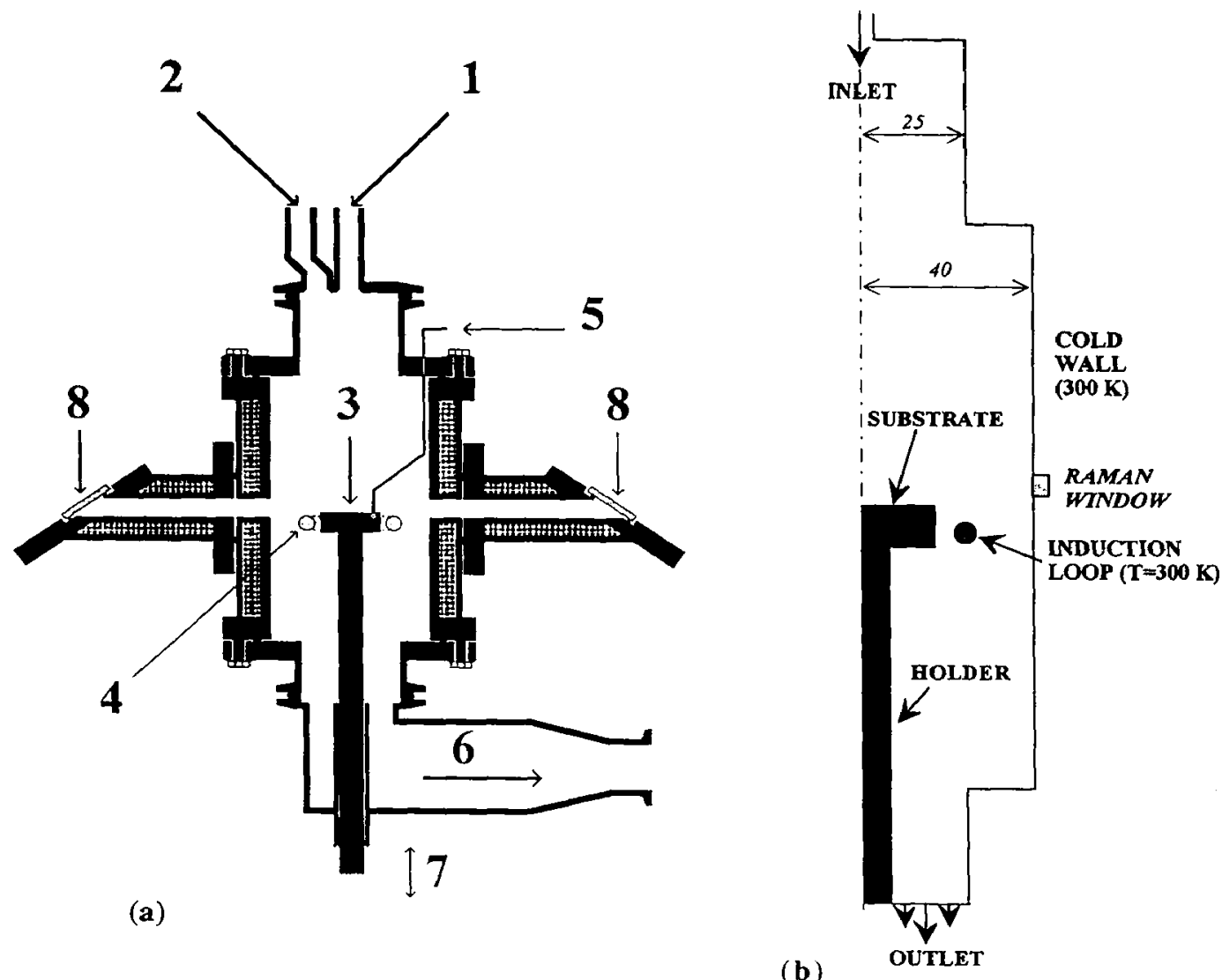

Figure 1 : (a) Cross section of the reactor : 1 - Gas mixture inlet. 2 - Manometer outlet. 3 - Substrate. 4 - Induction loop. 5 Thermocouple. 6 - Gas outlet. 7 - Vertical displacement. 8 - Brewsterian Ca F2 windows. (b) schematic representation for simulation purposes (dimensions are in $\mathrm{mm}$ )

\section{RAMAN EQUIPMENT AND MEASUREMENTS}

The temperature and the composition of the reacting gaseous mixture were determined at several points of the reactor by means of Raman spectrometry. The Raman equipment used in this work has already been described [13]. The reactor was put inside the cavity of an argon ion laser (figure 1). The density of radiation is about 50 times higher inside the cavity than in the emerging beam of the same laser in its conventional configuration. The spectrometer was an OMARS 89 from Dilor, equipped with an intensified multi-channel detection. Thanks to the intra-cavity excitation and the intensified detection, the whole set has a high detectivity : we were able to observe the $v_{1}$ band of tungsten hexafluoride ant to obtain a fair estimate of the temperature from this signal in a gas mixture in which the molar fraction of tungsten hexafluoride corresponded to a partial pressure of $14 \mathrm{~Pa}$ at $298 \mathrm{~K}$. The investigated points were located along the reactor axis at 2.5,5 and $10 \mathrm{~mm}$ from the substrate. The spectral resolution of the measurements was defined by the volume « seen » by the spectrometer which was approximately a cylinder of $60 \mu \mathrm{m}$ in diameter and $280 \mu \mathrm{m}$ in length. 
Temperature as well as composition determinations is based on Raman intensity ratio measurements. A particular care was taken to improve the accuracy and reproducibility of such measurements. Temperature was independently determined from the intensity ratio of two rotational lines of hydrogen and from the profile of the $v_{1}$ band of tungsten hexafluoride. For this last determination, we have developed a new method. At a given point, the temperature determined from the intensity of the rotational lines of hydrogen and that obtained from the $v_{1}$ band of tungsten hexafluoride might be somewhat different. In such cases, an average value was used for the modelling.

The composition of the reacting mixture was deduced from the relative intensities of the $v_{1}$ band of tungsten hexafluoride and of the rotational line of hydrogen. after a temperature correction. Hydrogen fluoride, a reaction product, gives Raman signals of so poor intensity that they were not suitable for concentration measurements in the present work, but the composition of the gaseous phase was completely defined by the molar fraction ratio $\mathrm{x}_{\mathrm{WF}_{6}} / \mathrm{x}_{\mathrm{H}_{2}}$.

Typical Raman spectra are given on figure 2 for two different temperatures of the substrate. When moving nearer the substrate, the intensity of the $v_{1}$ band of tungsten hexafluoride obviously decreases, and the intensity ratios of the rotational lines of hydrogen change, showing an increase of temperature.

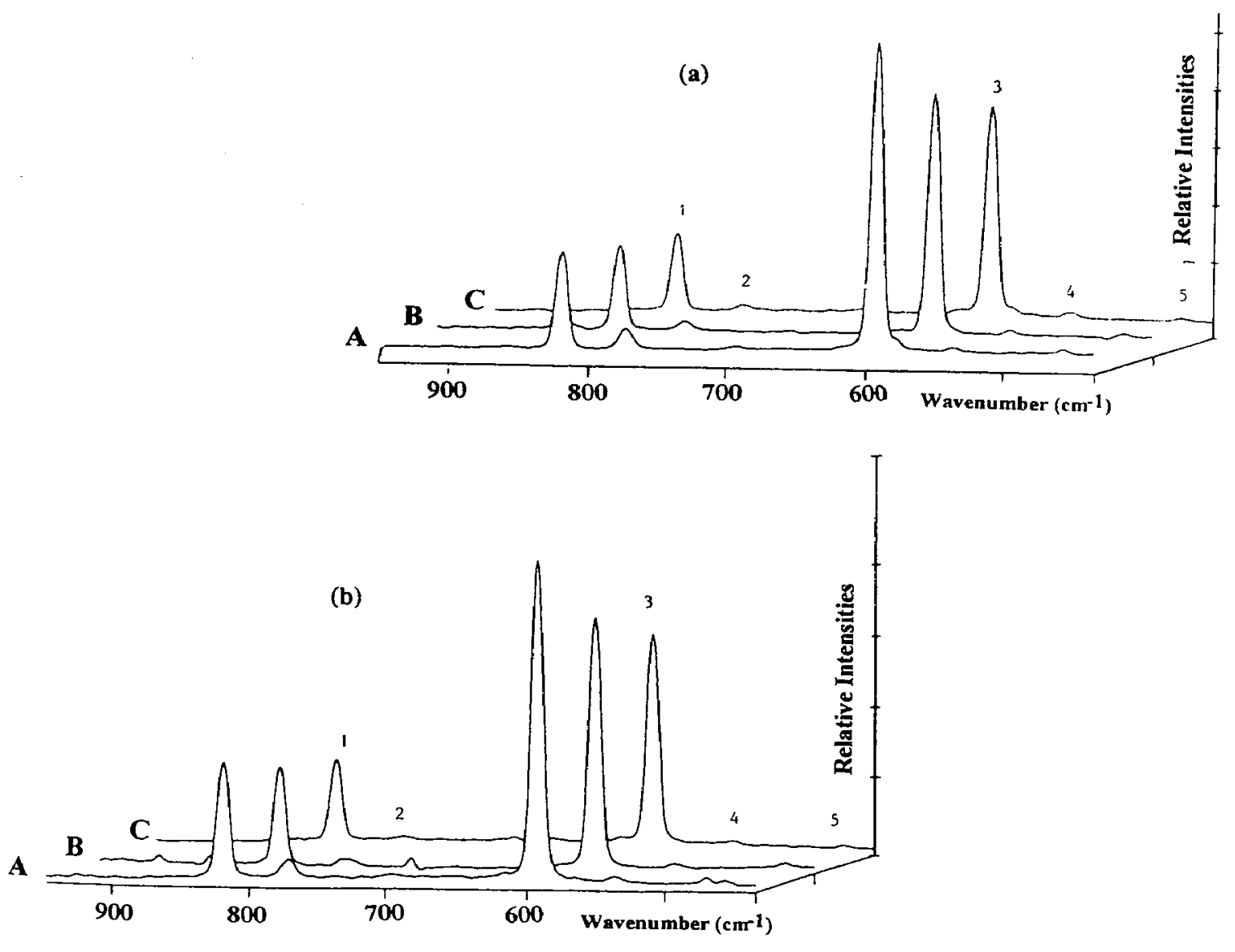

Figure 2 : 3-D representation of Raman spectra of the reacting mixtures at various distances from the substratc (10, 5 , 2.5 $\mathrm{mm}$ ) and for different substrate temperatures. The common parameters for both experiments are : $\mathrm{P}=4000 \mathrm{~Pa}:$ initial mole friktion ratio of WFG: 4 mole $\%:$ inlet flow rate $=200$ secm (STP). Distance form the substrate: $(A) 10$ mm. (B) 5 mm. (C)

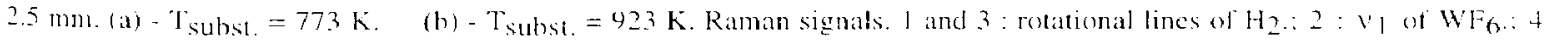
and 5 : rotationial lines of $\mathrm{HF}^{\mathrm{F}}$. 


\section{MODELLING OF TUNGSTEN DEPOSITION}

An isothermal, uniform velocity hydrogen gas mixed with tungsten hexafluoride enters at the top. The film deposition surface is a cylinder ( $33 \mathrm{~mm}$ (diameter) ; $10 \mathrm{~mm}$ (height)) heated by an induction coil and its temperature is kept constant. The sidewalis and the induction coil are water-cooled. As the flow proceeds downstream, the deposition of tungsten takes place with velocity, temperature and species $\mathrm{WWF}_{6}, \mathrm{HF}$ and $\mathrm{H}_{2}$ ) concentration fields interacting among themselves through mass transport and chemical reactions.

The multicomponent transport model has been already outlined [14]. On the substrate, the $\mathrm{H}_{2}$ reduction of $\mathrm{WF}_{6}$ takes place ; the surface reaction rate is expressed as a function of kinetic or mass transport limitations [14]. The transport and chemistry models are similar to the models presented by Kleijn et al. [9].

To solve the set of governing equations numerically along with appropriate boundary conditions, the finite element method was used. There were solved in two-dimensional, axisymmetric form. We have used Flux-Expert [15] which is a general-purpose simulation package : the CVD application was customized.

Some examples of the gas flow velocity in the reactor are shown in figure 3 . Some buoyancy flow pattern have been identified at the entrance region due to the small inlet tube. In the $773 \mathrm{~K}-1073 \mathrm{~K}$ temperature range, for the lowest pressure used $\left(P=4 \times 10^{3} \mathrm{~Pa}\right)$, for an inlet flow of $200 \mathrm{sccm}(8 \mathrm{sccm}$ $\left.\mathrm{WF}_{6}\right)$ a perfect laminar flow is established near the substrate. When the pressure is higher $\left(\mathrm{P}=10^{4} \mathrm{~Pa}\right)$, buoyancy-driven flows, on account of thermal and concentration gradients, arise over and under the substrate (fig. $3(\mathrm{~b})$ ). The temperature and $\mathrm{WF}_{6}$ concentration contours are shown in figure 4.

Figure 5 summarises the main results. It shows that the model accurately predicts the temperature dependence of the deposition rate, including the transition point where the reaction becomes transfer limited, circa $773 \mathrm{~K}$, for a pressure of $4 \times 10^{3} \mathrm{~Pa}$, a total flow rate of $200 \mathrm{sccm}$ and a $W_{6}$ molar fraction of $4 \%(8 \mathrm{sccm})$. The predicted deposition rates are the averaged values of the deposition rate calculated over the substrate because its shape is rather complex and the thickness of the coating is not uniform (figures 6 and 7). These results which have been confirmed experimentally, can be explained on the basis of convective effects at the substrate edges and near the induction coil and to rapid depletion of $\mathrm{WF}_{6}$ along the substrate [14].

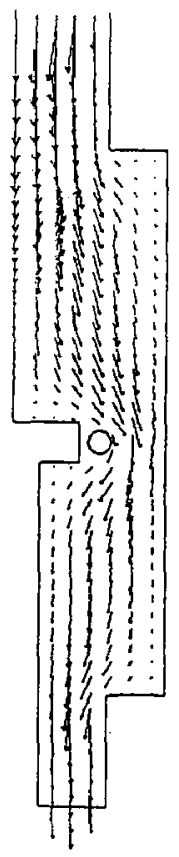

(a)

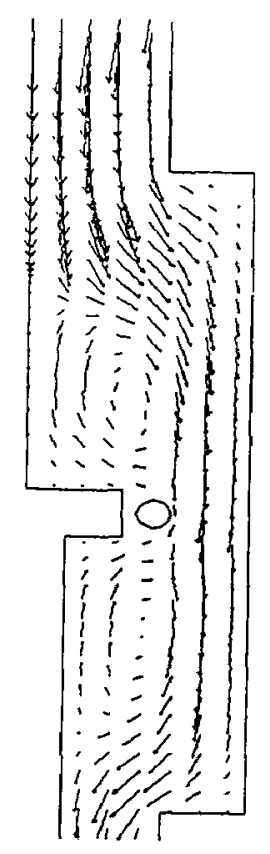

(b)

Figure 3: Model predictions of the velocity field features for an inlet flow (STP) of $200 \mathrm{sccm}, 8 \mathrm{sccm} \mathrm{WF}_{6}(4 \%)$ and a substrate temperature of $1073 \mathrm{~K}$. (a) $\mathrm{P}=4 \times 10^{3} \mathrm{~Pa}$; (b) $\mathrm{P}=10^{4} \mathrm{~Pa}$ (enlarged view). 


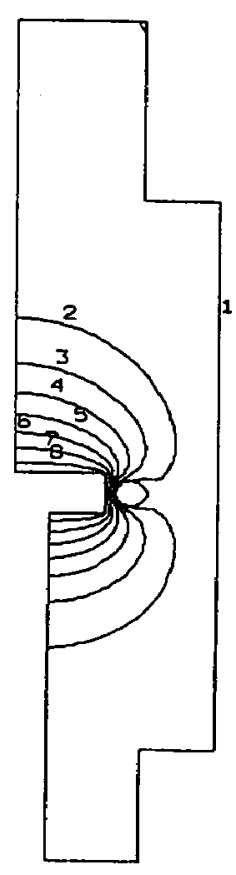

(a)

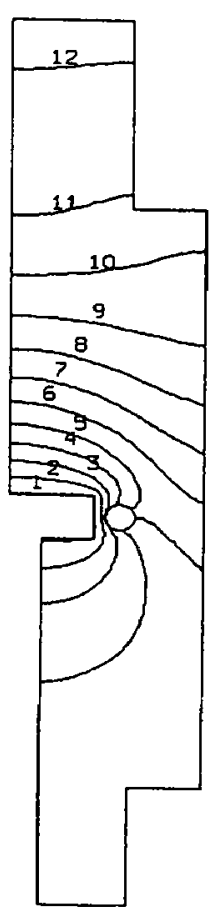

molar fraction

$\mathbf{T}(\mathbf{K})$

2: 400

3: $\mathbf{5 0 0}$

$4: 600$

$5: 700$

$6: 800$

$7: 900$

$8: 1000$

(b) (x 102)

$1: 0.363$

$2: 0.689$

$3: 1.016$

$4: 1.343$

$5: 1.669$

$6: 1.996$

$7: 2.323$

$8: 2.649$

$9: 2.976$

$10: 3.303$

$11: 3.630$

$12: 3.956$

Figure 4 : (a) Temperature and (b) $\mathrm{WF}_{6}$ concentration contours inside the CVD reactor for the conditions of figure 3 (a).

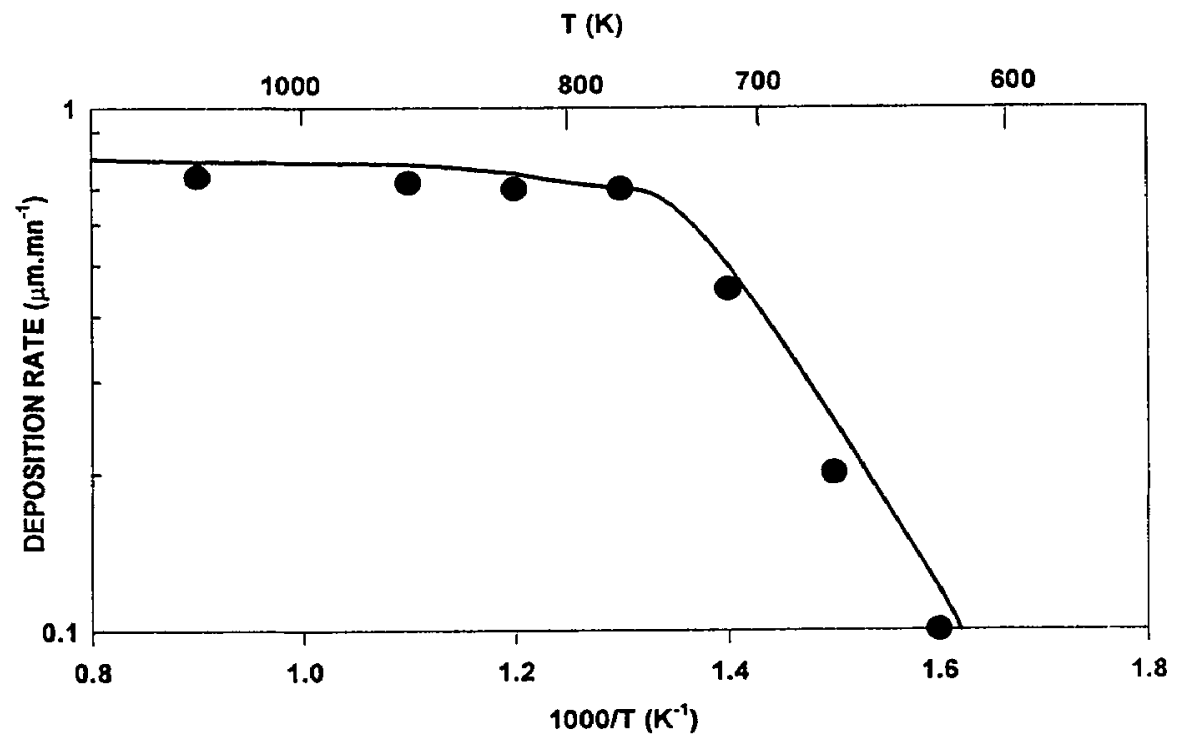

Figure 5 : Arrhenius plot for a total pressure of $4.10^{3} \mathrm{~Pa}$, an inlet flow of $200 \mathrm{sccm}\left(8 \mathrm{sccm} \mathrm{WF}_{6}(4 \%)\right)$ :--- modelling results : experimental points 


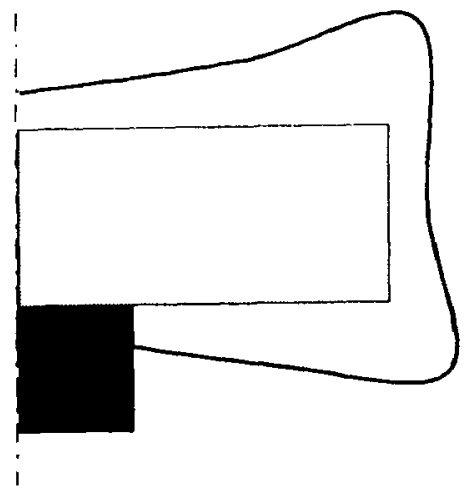

Figure 6 : Schematic representation of the uniformity of the coating for an inlet flow of $200 \mathrm{sccm}, 8 \mathrm{sccm}$ WF 6 (4\%). total pressure of $4.10^{3} \mathrm{~Pa}$ and a substrate temperature of $1073 \mathrm{~K}$ (only the right part of the substrate is shown)

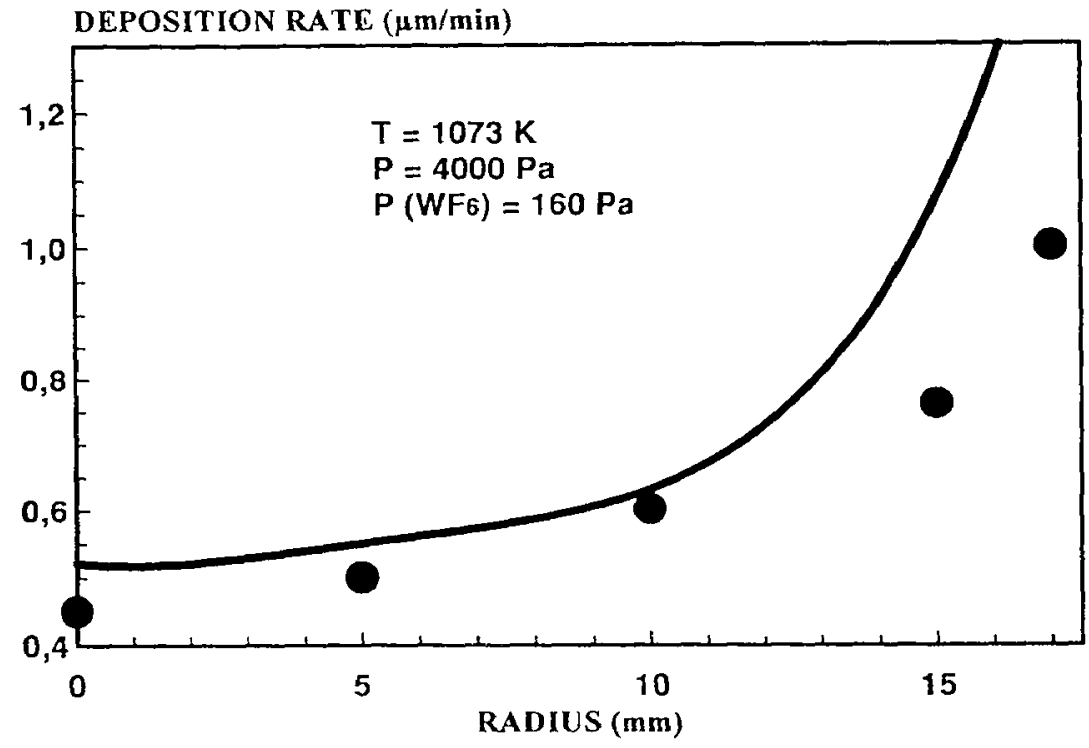

Figure 7 : Uniformity of the coating along the substrate radius: -_ modelling results . experimental points (same conditions as in figure 6)

\section{RAMAN DIAGNOSTICS AND MODELLING RESULTS}

Previous results have compared a model involving coupled phenomena and the main results of the reactive process : the deposition rate. More specific diagnostics are necessary to improve the accuracy of the proposed modelling. With the Raman equipment, previously described, we have measured the temperature and the concentrations of the reactive species in the gas phase over the substrate during the deposition 
process. For a fixed total flow of $200 \mathrm{sccm}$ and for different substrate temperatures, pressures and $\mathrm{WF}_{6}$ flow rates, the temperature and the $\mathrm{WF}_{6}$ concentration were measured and computed from the substrate ( 7 . $=0)$ to $5 \mathrm{~mm}$ above the substrate along the symmetry axis. Tables 1 and 2 show the two sets of results. They have been obtained by two quite different approaches and without any fitting parameters. It is not possible at present time to propose a precise discussion about the discrepancies between the two sets of results. They are inherent in the methods. It is possible to point out that the results are of the same magnitude. The authors think that the modelling results accurately describe the deposition of tungsten by the $\mathrm{H}_{2}$ reduction of $\mathrm{WF}_{6}$ in the temperature and pressure ranges investigated. Small errors could come from the determination of transport coefficients. The Raman measurements are perhaps subject to larger errors. However the temperature and $\mathrm{WF}_{6}$ partial pressure can be recorded by the Raman equipment presented which can contribute to the process control. These preliminary results are encouraging owing to the fact that no fitting parameters have been used between the experimental and modelling routes. The adjustment of the two approaches could be performed in the future to improve the accuracy of the modelling data and of the measured data.

Table 1 : Comparison between measured and predicted values assuming that the deposition process is mass transport controlled.

\begin{tabular}{|c|c|c|c|c|}
\hline \multicolumn{5}{|c|}{ Total flowrate $=200 \mathrm{sccm}(\mathrm{STP}) ;$ Total pressure $=4 \mathrm{kPa} ; \mathrm{WF}_{6}$ mol fraction $=4 \%$} \\
\hline $\begin{array}{l}\text { Distance from } \\
\text { substrate }(\mathrm{mm})\end{array}$ & $\begin{array}{c}\text { Averaged measured } \\
\text { temperature }(K)\end{array}$ & $\begin{array}{c}\text { Computed } \\
\text { temperature }(K)\end{array}$ & $\begin{array}{l}W_{6} \text { mol fraction } \\
\text { measured }\left(x \quad 10^{2}\right)\end{array}$ & $\begin{array}{l}\text { WF }_{6} \text { mol fraction } \\
\text { computed }\left(x 10^{2}\right)\end{array}$ \\
\hline \multicolumn{5}{|c|}{$\mathrm{T}=773 \mathrm{~K}$} \\
\hline 2.5 & 745 & 728 & 0.14 & 0.15 \\
\hline 5 & 712 & 685 & 0.25 & 0.19 \\
\hline \multicolumn{5}{|c|}{$T=923 \mathrm{~K}$} \\
\hline 2.5 & 843 & 867 & 0.13 & 0.12 \\
\hline 5 & 820 & 808 & 0.185 & 0.14 \\
\hline \multicolumn{5}{|c|}{$\mathrm{T}=1073 \mathrm{~K}$} \\
\hline 2.5 & 995 & 1002 & 0.14 & 0.10 \\
\hline 5 & 978 & 932 & 0.19 & 0.17 \\
\hline
\end{tabular}

Table 2 : Comparison between measured and predicted values assuming that the deposition process is kinetically controlled.

\begin{tabular}{|c|c|c|c|c|}
\hline \multicolumn{5}{|c|}{ Total flow rate $=200 \mathrm{sccm}(\mathrm{STP}) ;$ Total pressure $=1 \mathrm{kPa} ; \mathrm{WF}_{6}$ mol fraction $=8,5 \%$} \\
\hline $\begin{array}{c}|c| \\
\text { Distance from } \\
\text { substrate }(\mathrm{mm})\end{array}$ & $\begin{array}{c}\text { Averaged measured } \\
\text { temperature }(\mathrm{K})\end{array}$ & $\begin{array}{c}\text { Computed } \\
\text { temperature }(\mathrm{K})\end{array}$ & $\begin{array}{c}\mathrm{WF}_{6} \text { mol fraction } \\
\text { measured }\left(\times 10^{2}\right)\end{array}$ & $\mathrm{WF}_{6}$ mol fraction \\
compured $\left(\times 10^{2}\right)$
\end{tabular}




\section{CONCLUSION}

A model has been developed for the calculation of reactive mass transport occurring during the deposition of thick tungsten coatings at high temperature $(773-1073 \mathrm{~K})$ in a reactor resulting from the miniaturisation of an industrial one. The agreement between the computed and experimental results obtained from microscopic examinations and from in-situ Raman measurements demonstrates the validity of the proposed model and its predictive capabilities. We have investigated a temperature range (773 - $1073 \mathrm{~K})$ little studied owing to the importance of tungsten CVD processed at temperatures lower than $773 \mathrm{~K}$ for metallization problems in microelectronics. The physical and chemical phenomena involved during the high temperature deposition process are similar to those observed at lower temperatures. Finally we have shown that the temperatures and the $\mathrm{WF}_{6}$ partial pressures can be recorded by a Raman equipment during the deposition process.

\section{Acknowledgements}

This work was financially supported by Comhurex company and Le Carbone Lorraine. The authors acknowledge the referee for valuable recommendations.

\section{References}

[1] Broadbent E.K., Ramiller C.L., J. Electrochem. Soc., 131 (1984) 1427-1433.

[2] Mc Conica C.M., Krishnamani K., J. Electrochem. Soc., 133 (1986) 2542-2548.

[3] Pauleau Y., Lami P., J. Electrochem. Soc., 132 (1985) 2779-2784.

[4] Creighton J.R., Parmeter J.E., Critical Reviews Solid State Mater. Sci., 18 (1993) 175-238.

[5] Mc Inerney E.S., Chin B.L., Broadbent E.K.. in Tungsten and other Advanced Metals for VLSI Applications, G.C. Smith and R. Blumenthal Eds. (Materials Research Society, Pittsburg, PA, 1991) pp. 249-256.

[6] Gaillard D., Mat. Tech., 3 (1989) 1-16.

[7] Fotiadis D.I., Boekholt M., Jensen K.F., Richter W., J. Crystal Growth, 100 (1990) 577-599.

[8] Kleijn C.R., Werner C., Progress in Numerical Simulation for Microelectronics, Vol. 2, K. Merten and A. Gilg Eds. (Birkhaüser Verlag Basel, 1993) pp. 83-136.

[9] Kleijn C.R., Hasper A., Holleman J., Hoogendoorn C.J., Middelhoek J., J. Electrochem. Soc.. 138 (1991) 509-517.

[10] Werner C., Ulacia J., Hoffmann C., Flynn P., J. Electrochem. Soc., 139 (1992) 566-574.

[11] Devonshire R., Chemtronics, 2 (1987) 183-198.

[12] Osterlaken T.G.M., G.J. Leusink, Janssen G.C.A.M., Radelaar S., Kuijlaars K.J., Kleijn C.R., Van Den Akker H.E.A., J. Appl. Phys., 76 (1994) 3130-3139.

[13] Gaufrès R., Huguet P., Boya D., Lafforêt J., J. Phys. (France). C5 (50) (1989) 855-860..

[14] Pons M., Benezech A., Huguet P., Gaufres R., Diez P., Lafforet D., J. CVD, 2 (1993) 135-165.

[15] Flux-Expert Software Package Guide, 1993, DT2I, 38240 Meylan, France. 